\title{
PULMONARY GAS EXCHANGE: A COMPARISON OF THE EFFECTS OF SIGHS USING HELIUM AND OXYGEN WITH THE EFFECTS OF POSITIVE EXPIRATORY PRESSURE PLATEAU
}

\author{
K.W. TuRnBulL, B.A.SC., M.D."
}

Pertodic hyperanflations or "sighs" have been advocated by some to re-expand atelectatic lung ${ }^{1}$ thereby increasing arterial oxygen tension $\left(\mathrm{PaO}_{2}\right)$ and pulmonary compliance and reducing alveolar-arterial oxygen gradient $\left(\mathrm{A}-\mathrm{aDO}_{2}\right)$ and venous admixture or right-to-left pulmonary shunts $(\mathrm{Qs} / \mathrm{Qt})$. $^{2}$ Other investigators ${ }^{3,4,5}$ have failed to demonstrate any improvement in oxygenation after "sighs". On the other hand, Positive Expiratory Pressure Plateau (PEPP) has been shown to improve oxygenation by a similar mechanism. ${ }^{*}$

Inert gases, particularly nitrogen, ${ }^{7}$ are thought to have a direct role in preventing atelectasis. Helium is an inert gas which may be of benefit in this regard since its low solubility results in less absorption while its low density allows it to enter and leave small diameter airways easily, thus preventing "gas trapping", absorption and micro-atelectasis. ${ }^{8}$

This study is an attempt to compare "sighs" using oxygen and helium with PEPP and their effects on pulmonary gas exchange in a group of post-operative cardiac patients. They had cardiopulmonary by-pass procedures and had significant rightto-left shunts in the immediate post-operative period.

\section{Materlals and Methods}

The subjects for study were ten patients in the recovery room. They were free of chest disease or overt congestive heart failure. Median sternotomies with no entry into the pleural cavities had been done in all cases. Seven subjects had coronary by-pass graft procedures (CABG) for refractory angina pectoris. Two subjects (M.S. and M.B.) had mitral valve replacement (MVR) for refractory heart failure; the remaining one (D.P.) had a repair of a ventricular septal defect (VSD). The clinical details are shown in Table $\mathrm{I}$.

All subjects were intubated and on controlled ventilation with varying concentrations of oxygen using the same BIRD Mark 7 Respirator. They were ventilated with tidal volumes which ranged from 7 to $10 \mathrm{cc} / \mathrm{Kg}$ without "sighs" prior to the study period when the control or "initial" samples were taken. Endotracheal suction for secretion removal was performed on all subjects prior to the study period. They had indwelling arterial and central venous lines for continuous monitoring of blood pressures and pulse waves and for sampling of blood for analysis.

Two separate series of four "sighs," 20 seconds in duration and $30 \mathrm{~cm}$ water

- Clínical Research Fellow, Pulmonary Function Laboratory, Department of Anaesthesia, St. Paul's Hospital, University of British Columbia, Vancouver, British Columbia. 
TABLE 1

Details of Pateents Studied

\begin{tabular}{|c|c|c|c|c|}
\hline Patient & Age & Sex & Weight $(\mathrm{Kg})$ & Surgical procedure \\
\hline $\begin{array}{l}\text { PC } \\
\text { MP } \\
\text { DP } \\
\text { GMcI } \\
\text { PR } \\
\text { AP } \\
\text { BMcM } \\
\text { MS } \\
\text { MB; }\end{array}$ & $\begin{array}{l}51 \\
28 \\
50 \\
54 \\
55 \\
42 \\
50 \\
51 \\
35 \\
54\end{array}$ & $\begin{array}{l}\mathbf{M} \\
\mathbf{F} \\
\mathbf{M} \\
\mathbf{M} \\
\mathbf{M} \\
\mathbf{M} \\
\mathbf{M} \\
\mathbf{F}\end{array}$ & $\begin{array}{l}78.2 \\
56 \\
83.6 \\
76 \\
70.8 \\
87 \\
75.4 \\
68.5 \\
64 \\
61.5\end{array}$ & $\begin{array}{l}\text { Coronary artery bypass graft } \\
\text { Mitral valve replacement } \\
\text { Coronary artery bypass graft } \\
\text { Ventricular septal defect repair } \\
\text { Coronary artery bypass graft } \\
\text { Coronary artery bypass graft } \\
\text { Coronary artery bypass graft } \\
\text { Coronary artery bypass graft } \\
\text { Mitral valve replacement } \\
\text { Coronary artery bypass graft }\end{array}$ \\
\hline
\end{tabular}

pressure in magnitude were administered over 80-second intervals, using 100 per cent oxygen and 100 per cent helium with an Ambu bag. The terminal outlet of the bag was blocked to prevent dilution with room air. PEPP was applied by submerging the expiratory line $5 \mathrm{~cm}$ below water surface. The inflating pressures and tidal volumes were monitored at the endotracheal connector site. Ventilator settings with PEPP were adjusted with the aid of a Wright's Respirometer and a stopwatch to maintain the tidal volumes and time cycling present before the study, to prevent hypoventilation resulting from the increased airway resistance due to PEPP.

End-tidal gas samples were collected at the endotracheal connector site in $50 \mathrm{cc}$ syringes and blood samples were taken for analysis 10 minutes after each series of "sighs" or after 10 minutes of PEPP. The 10-minute period was allowed for alveolar-arterial-venous equilibration of carbon dioxide to a 90 per cent limit under controlled ventilation. ${ }^{9}$

Monitoring of alveolar carbon dioxide concentrations was done by connecting an endobronchial catheter to an infra-red rapid carbon dioxide analyzer ${ }^{*}$ previously calibrated with Scholandered gas samples. Alveolar oxygen concentration was based on oxygen concentration in the end-tidal gas samples. These were measured by a paramagnetic oxygen analyzert previously calibrated with Scholandered samples.

Arterial blood gas tensions and $\mathrm{pH}$ were measured with a Radiometer $\$ \mathrm{pH} /$ blood gas monitor and microelectrode unit at 37 degrees Centigrade $\left({ }^{\circ} \mathrm{C}\right)$. Calibration of this apparatus was made before and after each set of determinations. Corrections to body temperature were made when necessary. Samples were taken in heparinized plastic syringes, immediately iced and placed in a refrigerator at $4^{\circ} \mathrm{C}$ and analyzed within 30 minutes.

Alveolar to arterial oxygen gradients and carbon dioxide gradients were derived directly, e.g. $A a D O_{2}=\mathrm{P}_{E T} \mathrm{O}_{2}-\mathrm{P}_{\mathrm{n}} \mathrm{O}_{2}$ where $\mathrm{P}_{\mathrm{ET}} \mathrm{O}_{2}=\left(\% \mathrm{O}_{2 \mathrm{ET}}\right)\left(\mathrm{P}_{\mathrm{E}}-\mathrm{P}_{\mathrm{B}_{2} \mathrm{O}}\right)=\mathrm{P}_{\mathrm{A}} \mathrm{O}_{2}$ in the shunt equation. The equation used for calculating shunt in the present study was: ${ }^{10}$

$$
\mathrm{Qs} / \mathrm{Qt}=\frac{\mathrm{C}_{\mathrm{c}} \mathrm{O}_{2}-\mathrm{C}_{\mathrm{H}} \mathrm{O}_{2}}{\mathrm{C}_{\mathrm{o}} \mathrm{O}_{2}-\mathrm{C}_{\mathrm{v}} \mathrm{O}_{2}}=\frac{0.0031\left(\mathrm{P}_{\mathrm{A}} \mathrm{O}_{2}-\mathrm{P}_{\mathrm{Q}} \mathrm{O}_{2}\right)}{\mathrm{C}_{\mathrm{s}} \mathrm{O}_{2}-\mathrm{C}_{\mathrm{V}} \mathrm{O}_{2}+0.0031\left(\mathrm{P}_{\mathrm{A}} \mathrm{O}_{2}-\mathrm{P}_{\mathrm{a}} \mathrm{O}_{2}\right)}
$$

- Beckman Medical Gas Analyzer LB-1.

$¥$ Beckman Model E2 Rapid Oxygen Analyzer. $\quad$ tCopenhagen. 
where Qs/Qt is the ratio of quantity of blood flowing through the shunt to total quantity of blood flow (cardiac output) and $\mathrm{C}_{\mathrm{c}} \mathrm{O}_{2}, \mathrm{C}_{\mathrm{k}} \mathrm{O}_{2}, \mathrm{C}_{8} \mathrm{O}_{2}$ are oxygen contents of pulmonary capillary, arterial and mixed venous blood, respectively. When $\mathrm{P}_{\mathrm{a}} \mathrm{O}_{2}$ is greater than $150 \mathrm{mmHg}$ and haemoglobin is fully saturated the right-hand portion can be used. ${ }^{10}$ When the $\mathrm{P}_{\mathrm{n}} \mathrm{O}_{2}$ was less than $150 \mathrm{mmHg}$ and haemoglobin is not saturated, $\mathrm{C}_{\mathrm{c}} \mathrm{O}_{2}$ equalled $0.0031\left(\mathrm{P}_{\mathrm{A}} \mathrm{O}_{2}\right)+\mathrm{S}_{\mathrm{c}} \mathrm{O}_{2}(1.34)(\mathrm{Hb})^{11.12}$ and $\mathrm{C}_{\mathrm{a}} \mathrm{O}_{2}$ equalled $0.0031\left(\mathrm{P}_{\mathrm{n}} \mathrm{O}_{2}\right)+\mathrm{S}_{\mathrm{A}} \mathrm{O}_{2}(1.34)(\mathrm{Hb}) \cdot{ }^{11,12} \mathrm{C}_{\mathrm{a}} \mathrm{O}_{2}-\mathrm{C}_{7} \mathrm{O}_{2}$ was assumed to be six volumes $/ 100 \mathrm{ml} .{ }^{10}$ This was checked with the calculated oxygen content using arterial and central venous blood, which approximates true mixed venous blood, and no significant difference was found in this study.

Statistical evaluations were done using standard methods of calculation based on the "Student t-test" and Bessel's correction of the sample standard deviation, ${ }^{13}$

\section{Rezsults}

End-tidal oxygen concentrations immediately after the 100 per cent helium "sighs" were 20-25 per cent and no anoxia occurred. Cardiac output was not measured but no significant change occurred in heart rate, arterial pulse wave form, arterial blood pressure, central venous pressure or urine output during the study period.

Pulmonary gas exchange is summarized in Table II. Statistical analysis of these results are shown in the following table.

\section{Discussion}

This study showed that PEPP increased arterial oxygen tension in the postoperative patient and confirmed its beneficial effect as documented by other authors., ${ }^{6,14,16,18,18}$

"Sighs" performed with 100 per cent oxygen and 100 per cent helium failed to improve oxygenation of arterial blood in post-operative patients. Although ventilation improved after "sighs" of oxygen or helium as demonstrated by the increased

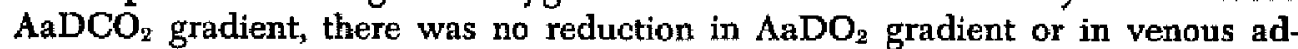
mixture. Despite the theoretical advantages of helium in preventing airway collapse, 8 its use with "sighs" was as ineffective as oxygen in the correction of pexfusion abnormalities. ${ }^{17,18}$ This improvement in oxygenation is likely to be due to the reduction in venous admixture $(\mathrm{Qs} / \mathrm{Qt})$ as a result of PEPP, as demonstrated in the patients in this series as well as in others., ${ }^{6,14,16}$ There is no evidence that other mechanisms responsible for improved oxygenation are involved. The partial pressure of oxygen in alveolar gas $\left(\mathrm{P}_{\mathrm{ET}} \mathrm{O}_{2}\right)$ showed no significant increase; there is no change in $\mathrm{PaCO}_{2}$ or in $\mathrm{AaDCO}_{2}$ to suggest improvement in ventilation or improvement in ventilation-perfusion ratio. McIntyre et $a l^{{ }^{8}}$ suggested that PEPP decreases venous admixture by the prevention of collapse of terminal airspace during expiration and thus PEPP may prevent atelectasis. Changes in diffusion probably did not play a significant role. The decrease in $\mathrm{AaDO}_{2}$ with PEPP corroborates this.

The use of PEPP did not result in an increased $\mathrm{P}_{\mathrm{ET}} \mathrm{O}_{2}$ as expected. When the Air-Mix venturi is functioning, as it was in this study, the BIRD respirator is a 


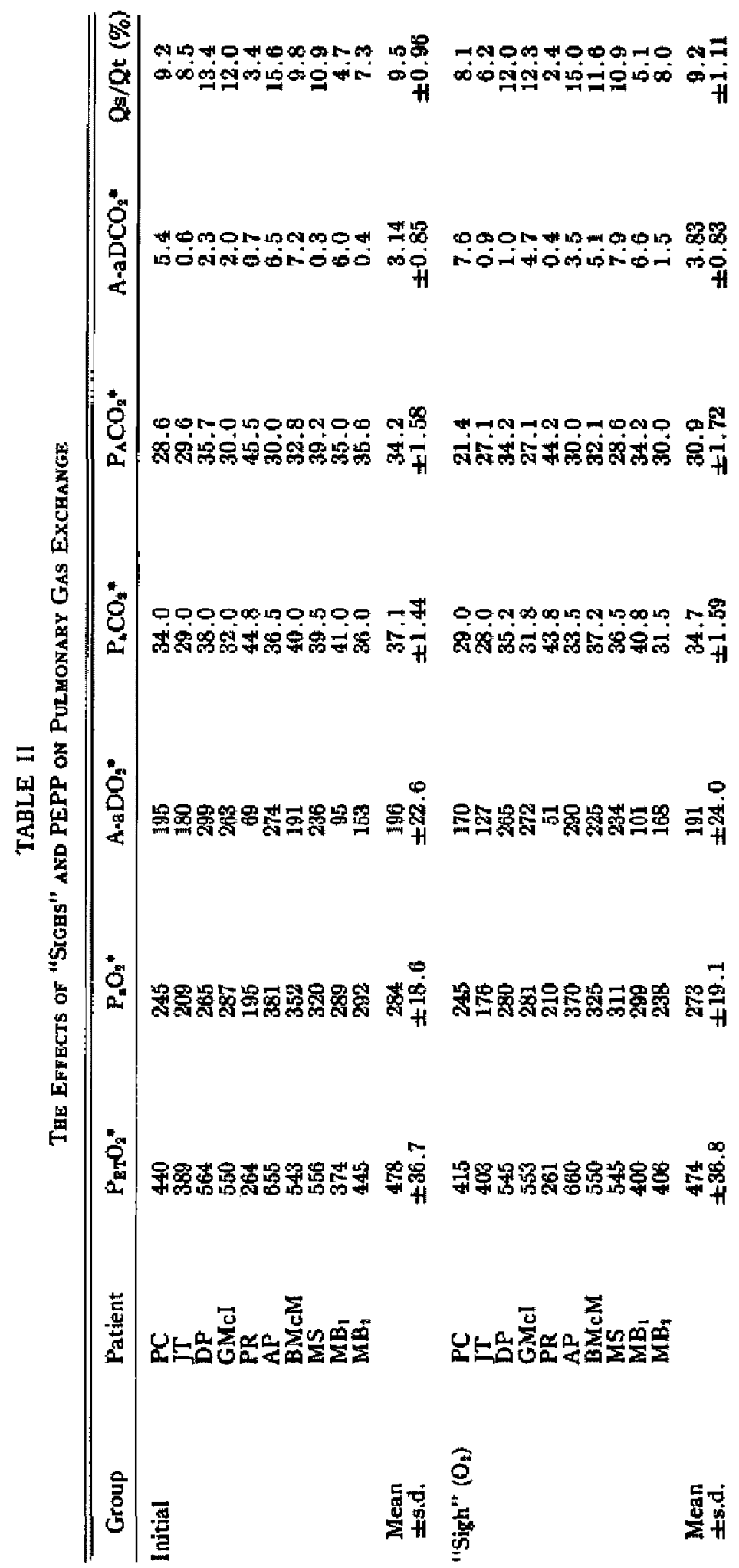




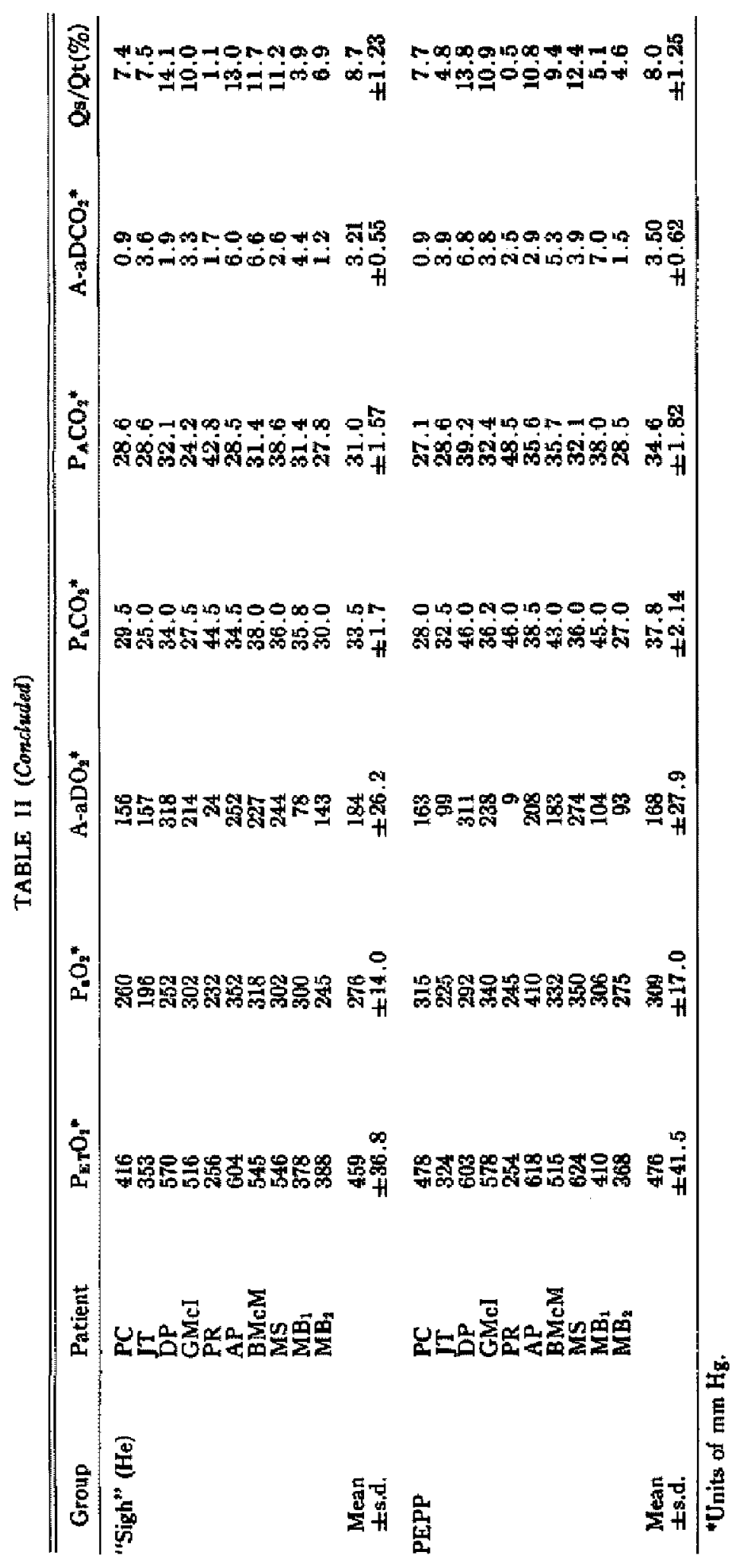


TABLE III

Summary of Statistical Analysis

1. A highly significant increase in $\mathrm{PaO}_{2}(p=0.01)$ with $\mathrm{PEPP}$ and no significant change with "sighs" of oxygen $\left(\mathrm{O}_{2}\right)$ or helium (He).

2. A significant decrease in $\mathrm{AaDO}_{2}$ with PEPP but no signifecant change with "sighs" of $\mathrm{O}_{\mathrm{a}}$ or He.

3. A highly significant decrease in Qs/Qt $(p=0.01)$ with PEPP and no significant change with "sighs" of $\mathrm{O}_{2}$ or $\mathrm{He}$.

4. A highty significant decrease in $\mathrm{PaCO}_{2}(p=0.01)$ with "sighs" of $\mathrm{O}_{2}$ or He and no significant change with PEPP.

5. A significant increase in $\mathrm{AaDCO}_{2}\left(p=0.05\right.$ ) with "sighs" of $\mathrm{O}_{2}$ and no signtficant change when "sighs" of He or PEPP were used.

6. No significant difference between $\mathrm{PaCO}_{2}$ resulting from "sighs" of $\mathrm{O}_{2}$ compared to "sighs" of He.

7. No significant change in $\mathrm{P}_{\mathrm{ET}} \mathrm{O}_{2}$ with "sighs" or PEPP.

constant pressure generator. ${ }^{19}$ Thus as patient resistance increases or as PEPP is added or increased, increased back pressure results and one would expect increased oxygen flow (the driving gas) to cycle the BIRD ventilator. The alteration in ventilator settings to counteract the decreased flow rates, peak pressure changes, decreased tidal volumes and cycling changes was not accompanied by a significant change of $\mathrm{P}_{\mathrm{ET}} \mathrm{O}_{2}$ with $5 \mathrm{cms}$ of PEPP. This suggests the pattern of ventilation initially and after PEPP was similar. ${ }^{20} A$ recent study by Davies, ${ }^{21}$ using a test lung, has graphically shown the detrimental changes which may occur with PEPP using a BIRD Respirator and emphasizes that the respirator will be dangerously ineffective if mechanical defects in the venturi, diaphragms or cycling system are present.

Adverse effects of PEPP, e.g. tension pneumothorax, decreased cardiac output, pulmonary capillary collapse, hypoventilation and/or arrhythmias did not occur. The use of a small pressure $\left(5 \mathrm{~cm} \mathrm{H}_{2} \mathrm{O}\right)$ for PEPP avoids complications and is adequate for improvement in oxygenation. $\mathrm{AaDO}_{2}$ and $\mathrm{Qs} / \mathrm{Qt}$ changes can be monitored as indices of improvement in each subject.

\section{Conclustons}

PEPP (with $5 \mathrm{~cm}$ of water) is superior to "sighs" in the post-operative patient with right-to-left shunts of 8 per cent or more. Use of PEPP results in a highly significant decrease in shunt (Qs/Qt) and highly significant increases in $\mathrm{PaO}_{2}$. PEPP applied on an intermittent basis may be anticipated as being more useful than "sighs" in the prevention of shunts and/or atelectasis. "Sighs" with oxygen or helium improve ventilation but not perfusion in the post-operative patient with a significant right-to-left shunt.

The BIRD Respirator can be adapted to function with PEPP and this increases the number of clinical situations where PEPP may be used.

\section{SUMMARY}

A comparison of periodic hyperinflations or "sighs" and positive expiratory pressure plateau (PEPP) was done in ten post-operative cardiac patients. Highly 
significant decreases in shunts (Qs/Qt) and highly significant increases in $\mathrm{P}_{\mathrm{B}} \mathrm{O}_{2}$ occurred with PEPP. Improvement in ventilation .occurred with "sighs" but no change in oxygenation or perfusion was observed. A BIRD respirator was used and was adapted to PEPP.

\section{RésUMÉ}

On a fait une comparaison entre l'hyperinflation périodique ou "soupirs" et le plateau de pression positive à l'expiration (PPPE) chez dix cardiaques en période post-opératoire. Il y a eu une diminution importante des shunts et une augmentation importante de la $\mathrm{P}_{\mathrm{i}} \mathrm{O}_{2}$ avec le PPPE. Il y a eu amélioration de la ventilation avec les "soupirs" mais on n'a observé aucun changement dans l'oxygénation ou la perfusion. On a utilisé un respirateur Bird et on l'a adapté au PPPE.

\section{ACKNOWLEDGMENTS}

I am grateful to Dr. R.T. Miyagishima and Dr. A.N. Gerein for allowing access to their patients for this study. I am particularly grateful to the Defence Research Board of Canada for financial support.

\section{REFERENCES}

1. Bendixen, H.H., Hedlex-Whyte, J, \& LAver, M.B. Impaired axygenation in surgical patients during general anesthetics with controlled ventilation. New England J. Med. 269: 991 (1963).

2. FalRLEY, H.B. \& Blenkan, G.D. Effect on pulmonary gas exchange of variations in inspiratory flow rate during intermittent positive pressure ventilation. Brit. J. 'Of Anaesth. 38: 320 (1966).

3. Nown, J.F., Bergman, N.A., \& Coleman, A.J. Factors infuencing the arterial oxygen tension during anesthesia with artificial ventilation. Brit. J. of Anaesth. 37: 389 (1965).

4. EumLey, ]., Mongan, M., \& Sykes, M.K. Changes in atterial oxygenation and physiological deadspace under anaesthesia. Brit. J. of Anaesth. 41:279 (1969).

5. PandaY, J. \& NunN, J.F. Faillare to demonstrate progressive falls of arterial $\mathrm{PO}_{2}$ during anaesthesia. Anaesthesia 23: 38 ( 1968 ).

6. McIntyre, R.W., Laws, A.K., Ramachandran, P.R. Positive expiratory pressure plateau: improved gas exchange during mechanical ventilation. Canad. Anaes. Soc. J. 16: $477(1969)$.

7. Browne, D.R., Rochrord, J., O'Connel, U, \& Jones, J.G. The incidence of postoperative atelectasis in the dependent lung following thoractomy: The value of added nitrogen. Brit. J. of Anaes. 42: 340. (1970).

8. VAIL, E. Hyperbaric respiratory mechanics. Aerospace Med. 42 (5): 536 (1971).

9. FENN, W.O. \& RAHN, H. (section eds.) Handbook of physiology, Section 3: Respiration, vol. 1. Washington: Waverley Press (1964).

10. LAver, M.B, \& SEIFzN, A. Measurement of blood oxygen tension in anesthesia. Anesthesiology 26: 73 ( 1965 ).

11. TheYF, $R$, Calculation of blood $\mathrm{O}_{2}$ content from optically determined $\mathrm{Fb}$ and $\mathrm{HbO}_{2}$. Anesthesiology 33: 653 (1970).

12. Pays-Ronents, C., Fözx, P., HAan, C.E.W. Caloulation of blood $\mathrm{O}_{2}$ in cotrespondence. Anesthesiology $34: 581$ (1971).

13. BanchorT, H. Introduction to biostatistias, 1st ed. New York: Hober-Harper (1957).

14. Hill, D.H., MAN, F.B., OsbonN, J.J., \& Genbone, F. Correct use of respirator on cardiac patient after operation. Arch. Surg. 91 : 775 (1965).

15. Asmbavah, D.C. Effect of ventilatory methods and patterns on physiological shunt. Surgery 68: $99(1970)$.

16. Kumar, A., Falme, K.J., Gefifin, B., Aldredoe, C.F, Laver, M.B., Lowenstein, E., \& 
Pontoppman, H. Continuous positive pressure ventilation in acute respiratory failure. New England J. of Med. 283: 1431 (1970).

17. LAws, A.K. \& McINrYme, R.W. Chest physiotherapy: A physiological assessment during intermittent pesitive pressure ventilation in respiratory failure. Canad. Antes. Soc. J. I6: 487 ( 1969 ).

18. Hansley, E., Louzada, N., Beckrake, M.R. To sigh or not to sigh. Am. Rev. Resp. Dis. 101: $611(1970)$.

19. Scuma, C. \& Feldman, S. (ed) Scientific foundations of anaes. Ist ed. London: Heinemann (1970).

20. PIence, A.K. Assisted respiration. Annual Review of Medicine 20: 431 (1969).

21. DAviss, D.W. The effects of adding a positive expiratory pressure plateau (P.E.P.P.) with controlled ventilation with a Bird Mark 7 or Mark 8 ventilator. Canad. Anaes. Soc. J. $19: 217$ (May, 1972). 